\title{
Cherubism: A case report
}

\author{
Priya Singh, Abhinav Singh, M Srinivasa Raju
}

\begin{abstract}
Introduction: Cherubism is a rare, nonneoplastic, fibro-osseous disorder seen in children which is characterized by bilateral painless enlargement of the jaws giving a cherubic appearance to the patient. It is an autosomal dominant disorder but may occur sporadically as well. The treatment of cherubism is contentious. It is said that the disease regresses by itself and even after regression, if any asymmetry is seen, the bony deformity can be corrected by decortications of bone and osseous shaving. Case Report: We describe a rare case of cherubism in a child who started developing bilateral, painless, facial swelling at the age of five years which continued till the age of twelve years without any regression of the lesions. Based on clinical, radiographical and histopathological findings, a diagnosis of cherubism was made. Conclusion: Cherubism should be considered in the differential diagnosis of young patients who present with bilateral mandibular swelling. Comprehensive clinical, radiological, and
\end{abstract}

Priya Singh ${ }^{1}$, Abhinav Singh², M Srinivasa Raju ${ }^{3}$

Affiliations: ${ }^{1}$ BDS, MDS, Senior Lecturer, Department of Oral Medicine \& Radiology, Saraswati Dental College and Hospital, Lucknow (UP), India; ${ }^{2}$ BDS, MDS, Senior Lecturer, Department of Conservative \& Endodontics, Saraswati Dental College and Hospital, Lucknow (UP), India; ${ }^{3}$ BDS, MDS, Professor \& HOD, Department of Oral Medicine \& Radiology, Saraswati Dental College and Hospital, Lucknow (UP) India.

Corresponding Author: Dr. Priya Singh, C-319, Nirala Nagar, Lucknow (U.P.) Pin - 226020, India; Mob: +91 9473871737, Landline No: 0522-2788280; Email: priyaz14@yahoo.com

Received: 01 September 2012

Accepted: 20 October 2012

Published: 01 May 2013 histopathological evaluation can facilitate the diagnosis of cherubism.

Keywords: Cherubism, Mandible, Follow-up, Bilateral

$* * * * * * * * *$

Singh P, Singh A, Raju MS. Cherubism: A case report. International Journal of Case Reports and Images 2013;4(5):260-265.

$$
* * * * * * * * *
$$

doi:10.5348/ijcri-2013-05-308-CR-5

\section{INTRODUCTION}

Cherubism is a benign condition that involves bilateral swelling of the maxilla and or the mandible. It was first described by Jones in 1933 as a familial multilocular cystic disease of the jaws [1]. Cherubism is a genetic disorder of the jaw characterized by bilateral, symmetrical enlargement of the mandible or maxilla resulting from rapid bone degradation followed by extensive bone remodeling with multilocular benign cysts. The facial appearance by the upwardly turning eyes and swollen cheeks have been described as resembling the faces of cherubs found in Renaissance art $[2,3]$. Typical age of onset is 2 to 5 years, with the jaw lesions progressing gradually until puberty when the swelling spontaneously stabilizes and then it regresses. The variable cherubism phenotype can range from absence of any clinical features to severe mandibular and maxillary over growth causing respiratory, vision, speech and swallowing problems. Radiographic changes can last up to the fourth decade. This disease usually affects the maxillofacial region and only rarely it may affect ribs and other long bones. It has a characteristic histopathological appearance [4, 5]. 


\section{CASE REPORT}

A 12-year-old male patient reported to the department of Oral Medicine and Radiology with a complaint of bilateral swelling of face and a protruding mass. The patient reported that before the age of five years he had normal facial features and no physical abnormality was present. From the age of seven years the patient noticed a swelling appearing on both sides of the face and he started looking different from other children in his locality. The swelling gradually increased in size. The concerned parents took him to a general physician, who diagnosed it as hyperparathyroidism. Since even after six months of medical treatment no regression of swelling was seen, the patient stopped taking medication for hyperparathyroidism. The family history revealed that none of his parents had any history of swelling of the face in their childhood.

On extraoral examination, patient's face had severe bilateral expansion with upturned eyes (Figure 1). The swelling was bony hard in consistency with obliteration of the vestibular depth. Bilateral submandibular lymph nodes were enlarged. On general physical examination no significant abnormality was detected. Intraoral examination showed that left upper and lower canine region had an exophytic growth. The growth was ovoid, bright red in color measuring about $1.5 \mathrm{x} 1 \mathrm{~cm}$ in size. The growths were non-tender, clearly defined, sessile with a smooth surface. The lesion was firm with absence of any pulsation and fluctuation (Figure 2). Dental occlusal and panoramic, PA mandible, hand-wrist and long bone radiographs were advised in the patient. Mandibular topographic occlusal radiograph showed bilateral multilocular lesions, multiple impacted teeth, expansion of buccal cortical plates and thinning of buccal and lingual cortices (Figure 3). Panoramic and PA mandible radiographs too showed multilocular lesions present bilaterally in the mandible causing extensive destruction of body of mandible and ramus bone along with multiple impacted teeth. (Figures 4,5 ). The radiographic features of multilocular radiolucency with floating teeth and multiple retained deciduous teeth were present. Hand-wrist and long bone radiographs did not show any abnormality (Figures 6, 7). All laboratory investigations including immunoassay for parathyroid hormone were found to be within normal limits. Since the previous diagnosis of hyperparathyroidism was incorrect, the patient was asked to discontinue the medicinal treatment for the same.

Histopathological examination of tissue obtained after incisional biopsy from exophytic growth present in left upper and lower canine region showed abundant plump fibroblast like cells with abundant multinucleated giant cells interspersed between them. Some areas of local hemorrhages were also noted within the loose connective tissue along with large number of dilated blood vessels (Figure 8). The histopathological features were suggestive of giant cell granuloma.
The clinical, radiological and histopathological findings confirmed the diagnosis of cherubism. After doing a detailed clinical review, it was decided that the patient will be kept under observation till he attains the age of puberty. Surgery, if required, will be decided at a later date.
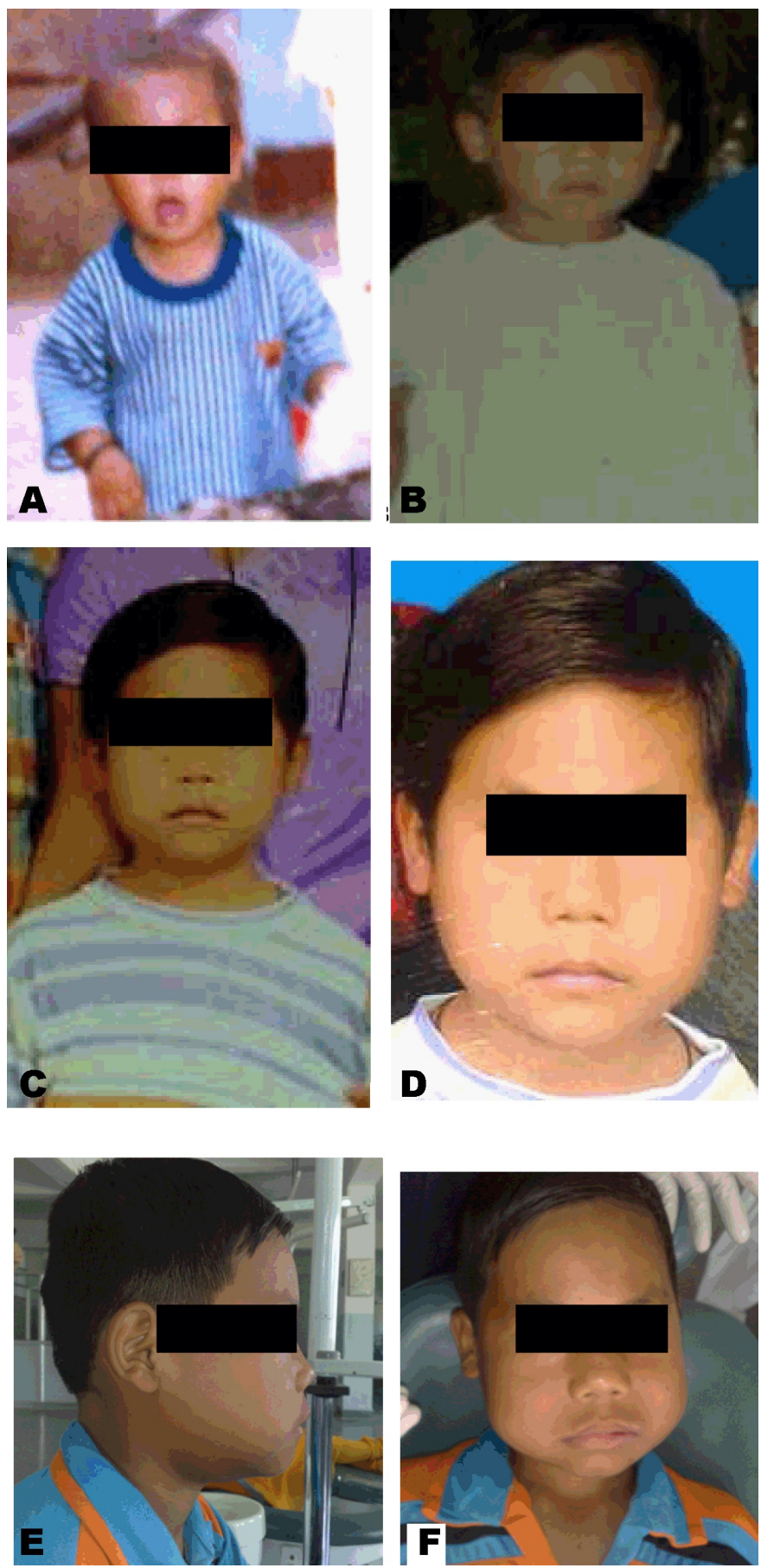

Figure 1: (A) Child at the age of two years, appears normal, (B) Child at the age of $3^{1 / 2}$ years, appears normal, (C) Child at the age of four and half years, appears normal, (D) Child at the age of seven years, shows initial enlargement of jaw, (E) Child at the age of 12 years showing bilateral swelling with characteristic, 'Cherub Face'. (F) Clinical picture showing development of bilateral swelling in a 12-year-old child. 

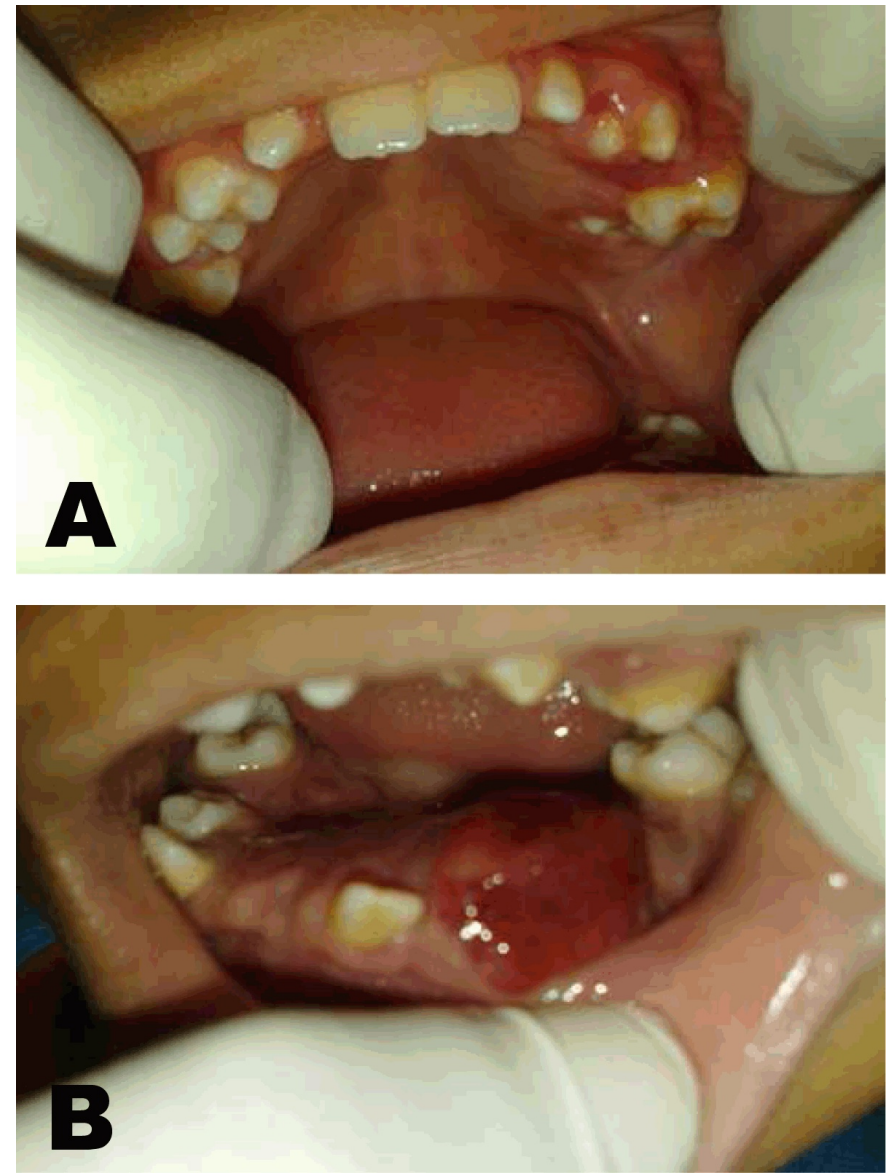

Figure 2: (A) The left upper canine region showed an exophtic growth, (B) The left lower canine region showed an exophtic growth.

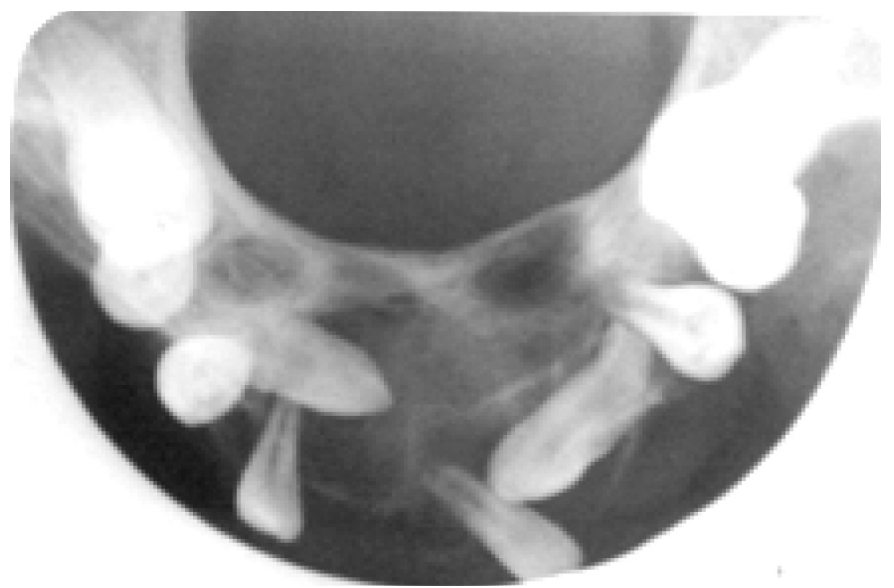

Figure 3: Topographic mandibular occlusal radiograph showing multilocular lesions bilaterally, buccal cortical plate expansion along with thinning of buccal and lingual cortical plates.

\section{DISCUSSION}

Jones et al. [1] first described familial occurrence of painless enlargement of the jaws in three siblings in the

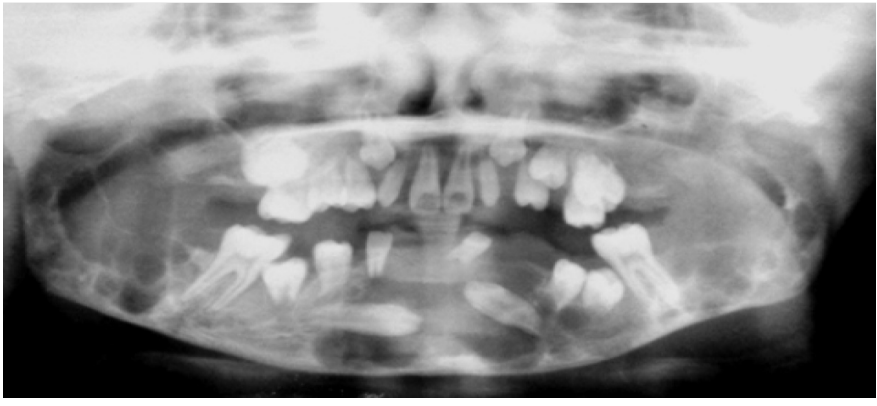

Figure 4: Panoramic view showing multilocular lesion in the mandible bilaterally, floating teeth and multiple impacted teeth.

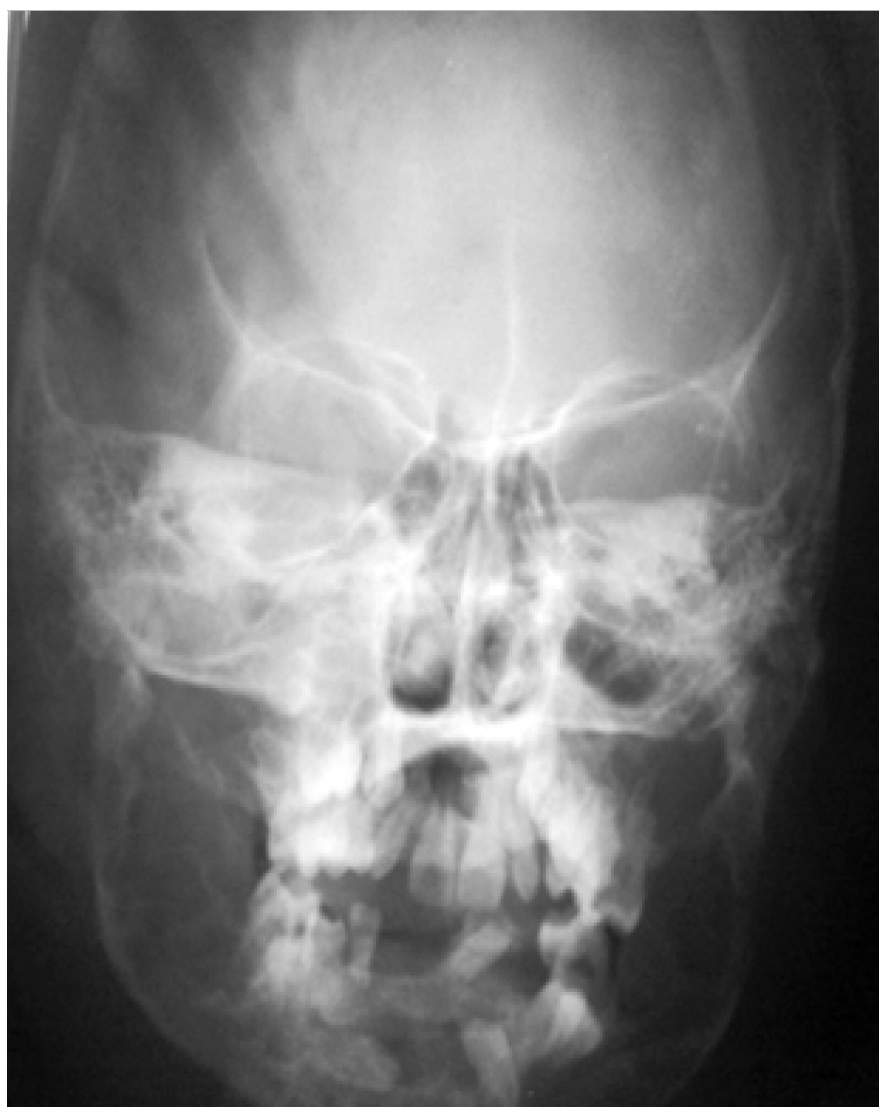

Figure 5: Posteroanterior mandibular radiograph showing bilateral multilocular lesions.

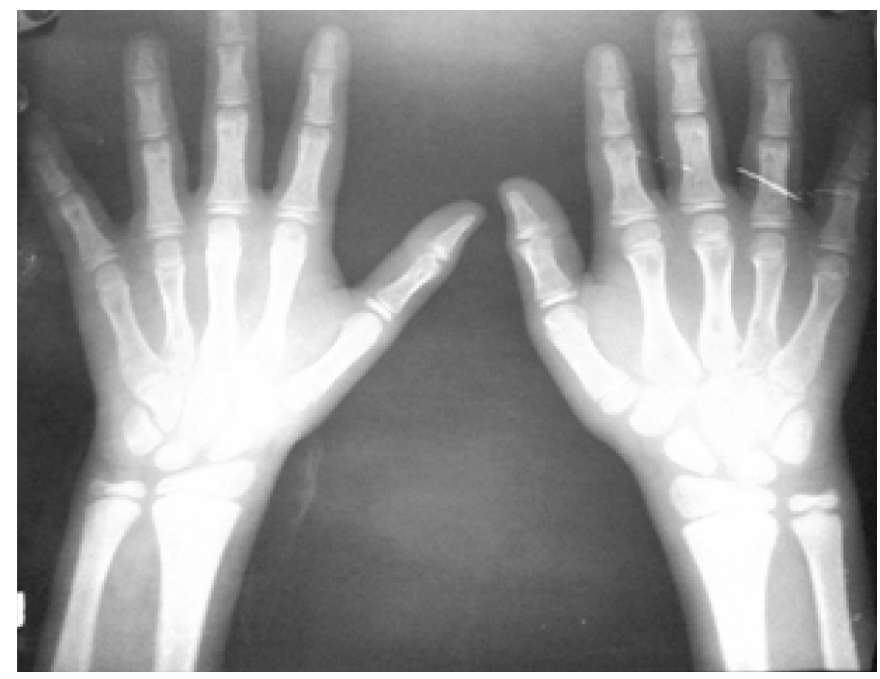

Figure 6: Hand-wrist radiograph showing no abnormality. 


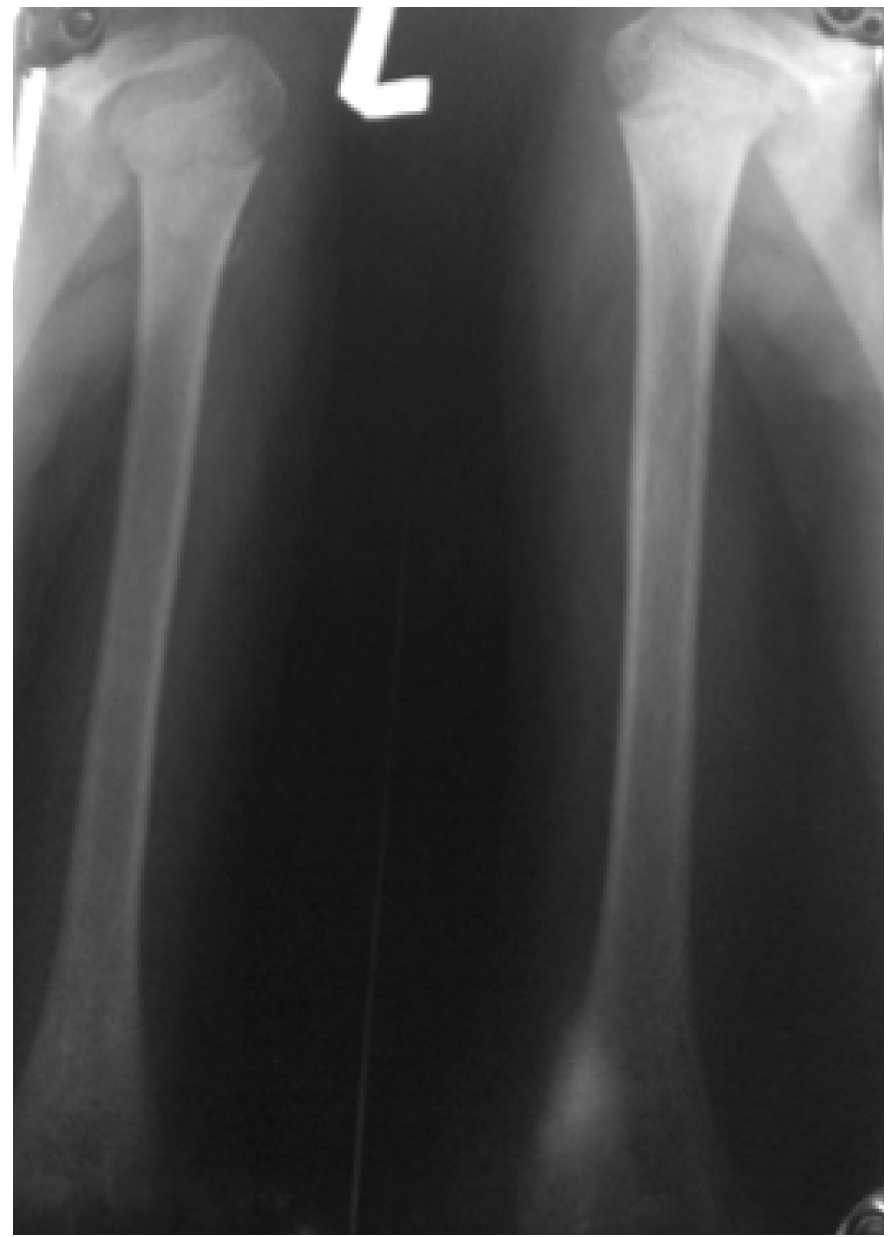

Figure 7: Long bone radiograph showing no abnormality.

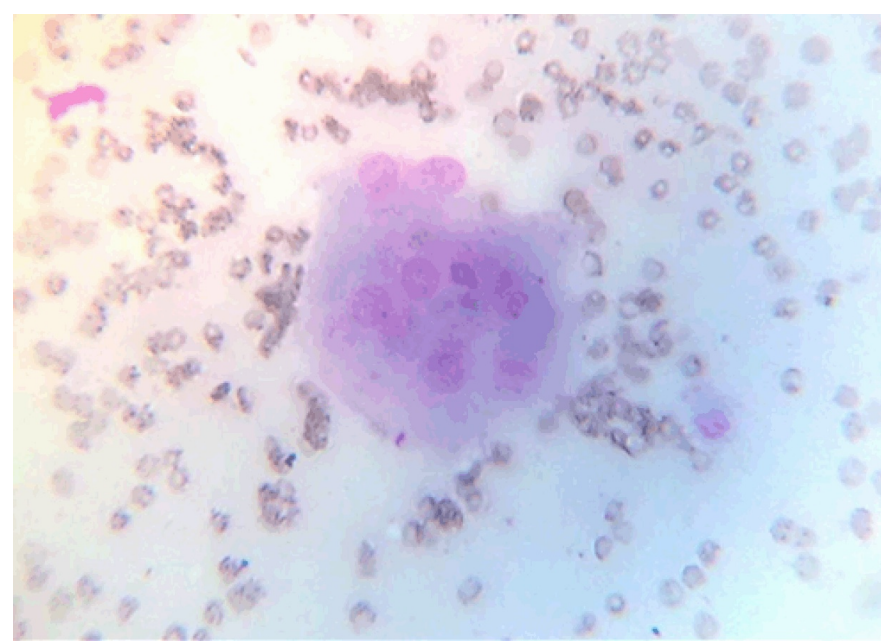

Figure 8: Multilocular giant cells suggestive of cherubism (H\&E stain, x400).

year 1933 and later coined the term "cherubism". The cherubs of Renaissance art showed similar full round cheeks and the upward gaze of the eyes giving the children a peculiarly grotesque, cherubic appearance [1-3]. Cherubism is also called familial fibrous dysplasia of the jaws, but the recent genetic mapping has shown it to be a separate entity at the molecular level [6]. The disease is a genetically mediated disorder which usually gets resolved after puberty. It is more common in males than females. It has a familial inheritance in approximately $80 \%$ cases with a variable expressivity in both jaws. Classically the patient is normal at birth; onset generally starts between 14 months to five years of age, however in severe cases it may be seen at the time of birth [7-9]. It keeps on progressing until puberty but in some cases it may resolve without any treatment. Typical features of cherubism are bilateral, painless enlargement of cheeks and the jaws, loss of bone in the jaws and its replacement with large amount of fibrous tissue, fullness of the lower half of the face, retraction of the lower lids by the stretched skin over the cheeks because of which a line of sclera is exposed and the eyes appear to be raised to heaven. In severe cases it may also include the coronoid process and condyles. Mandible is usually involved and in 60\% cases the maxilla may also be involved. There is premature loss of deciduous teeth and displacement of permanent dentitions. Submandibular lymph node enlargement is seen in $45 \%$ cases. Rarely the lesion may extend up to the orbit with loss of eyesight due to optic nerve atrophy. Upper airway involvement is rare. Displacement of tongue affecting the speech, mastication and swallowing is also seen in some cases. Extremely rare extra-facial skeletal involvement can be seen affecting the upper humorous, anterior ribs and upper femoral necks. All the above physical and clinical alterations can lead to psychological impairment [10-18].

Radiographically, cherubism is characterized by bilateral, expansive, multilocular, radiolucent lesions clearly delimited by cortical bone in the mandible. Bone alterations generally start in the angle and ascending ramus of the mandible. The changes may extend to involve the mandibular body, displace the mandibular canal and in some cases involve the coronoid process. Maxillary involvement is less frequent and less extensive $[1,3,4,10,12,15]$. In severe cases infiltration of orbital bone can occur leading to exacerbated exophthalmia which limits ocular movements. Hanging and floating teeth along with multiple retained deciduous teeth are also commonly seen. Different types of dental abnormalities ranging from delayed eruption, displacement of teeth to root resorption are known to occur [19-21].

Arnott et al. [22] proposed a grading system for cherubism, according to lesion location and the degree of expansion. Accordingly, grade 1 cases are limited to both ascending rami of the mandible, grade 2 cases involve the maxillary tuberosities and mandibular ascending rami and grade 3 cases correspond to massive involvement of both jaws except the coronoid processes and condyles resulting in considerable facial disfigurement. Ramon et al. [23] added grade 4 for cases where all of the classical features of the disorder exceeding grade 3 are present. The grade may change depending on findings at the follow-up examination. According to this classical grading system our patient 
belongs to grade 1 cherubism in which lesion is limited to both ascending rami of the mandible [21]. Hematoxylin and eosin stained sections reveal highly cellular fibrovascular connective tissue. The cellular component consisted of abundant plump fibroblast like cells with abundant multinucleated giant cells interspersed between them. Some areas of local hemorrhage was also present within the connective tissues. Large number of dilated blood vessels were noticed along with mixed type of inflammatory components. The histopathologic features are suggestive of giant cell granuloma [4, 8, 15, 16, 21, 24]. Furthermore, there is a necessity to distinguish cherubism from central giant cell granuloma and giant cell tumors of the hyperparathyroidism with which it holds a false synonymity $[5,13,14,25]$.

Mutations in the axon 9 of the $\mathrm{SH}_{3}$ domain binding protein 2 ( $\left.\mathrm{SH}_{3} \mathrm{BP} 2\right)$ genes on $\mathrm{Ch} 4 \mathrm{p}$ band 16.3 have been identified in many families with cherubism. Nonfamilial cases may also be due to new mutations. These mutations lead to the development of multiple cystic giant cell lesions in the jaw bones in early childhood with stabilization and resorption after puberty. Signals unique to mandible and maxilla, triggered by the eruption of secondary teeth and transmitted throughout the extracellular matrix are thought to be responsible for the organ specific changes seen in cherubism. So far, no disease causing mutation outside axon 9 in the $\mathrm{SH}_{3} \mathrm{BP} 2$ gene has been identified, making it specific for the diagnosis of the disease [25-27]. The treatment is based on the known natural course of the disease and the clinical behavior of the individual case. It ranges from masterly inactivity to recontouring for relieving complications and or cosmetic purposes. Therapy with calcitonin has been said to reduce the need for surgery by inducing bone resorption $[28,29]$.

\section{CONCLUSION}

In conclusion, we report a rare case of cherubism showing the classical clinical features, sequence of progression and radiographic presentations which are the main characteristics of the disease.

\section{Author Contributions}

Priya Singh - Substantial contributions to conception and design, Acquisition of data, Drafting the article, Revising it critically for important intellectual content, Final approval of the version to be published

Abhinav Singh - Substantial contributions to conception and design, Acquisition of data, Drafting the article, Revising it critically for important intellectual content, Final approval of the version to be published M Srinivasa Raju - Substantial contributions to conception and design, Acquisition of data, Drafting the article, Revising it critically for important intellectual content, Final approval of the version to be published

\section{Guarantor}

The corresponding author is the guarantor of submission.

\section{Conflict of Interest}

Authors declare no conflict of interest.

\section{Copyright}

(C) Priya Singh et al. 2013; This article is distributed under the terms of Creative Commons Attribution 3.0 License which permits unrestricted use, distribution and reproduction in any means provided the original authors and original publisher are properly credited. (Please see www.ijcasereportsandimages.com/copyright-policy.php for more information.)

\section{REFERENCES}

1. Jones WA. Familial multilocular cystic disease of the jaws. Am J Cancer 1933;17:946-50.

2. Khalifa MC, Ibrahim RA. Cherubism. J Laryngol Otol 1988;102(6):568-70.

3. Burland JG. Cherubism: familial bilateral osseous dysplasia of the jaws. Oral Surg Oral Med Oral Pathol 1962;15(Suppl 2):43-69.

4. Gomes MF, de Souza Setubal Destro MF, de Freitas Banzil EC, dos Santos SH, Claro FA, de Oliverira Nogueira T. Aggressive behaviour of cherubism in a teenager: 4-years of clinical follow-up associated with radiographic and histological features. Dentomaxillofac Radiol 2005;34(5):313-8.

5. Peters WJ. Cherubism: A study of twenty cases from one family. Oral Surg Oral Med Oral Pathol 1979;47(4):307-11.

6. Jain V, Gamanagatti SR, Gadodia A, Kataria P, Bhatti SS. Non-familial Cherubism. Singapore Med J 2007;48(9):e253-7.

7. Cabral CA, dos Santos GM. Cherubism. Ars Curandi Odontol 1977;4(4):44-51.

8. Ayoub AF, el-Mofty SS. Cherubism: report of an aggressive case and review of literature. $\mathrm{J}$ Oral Maxillofac Surg 1993;51(6):702-5.

9. Kozakiewick M, Perczynska-Partyka W, Kobos J. Cherubism--clinical picture and treatment. Oral Dis 2001;7(2):123-30.

10. Pontes FS, Ferreira AC, Kato AM, et al. Aggressive case of cherubism: 17-year follow-up. Int J Pediatr Otorhinolaryngol 2007;71(5):831-5.

11. Sarda D, Kothari P, Kulkarni B, Pawar P. Cherubism in siblings: A case report. J Indian Soc Pedod Prev Dent 2007;25(1):27-9.

12. Carvalho Silva E, Carvalho Silva GC, Vieira TC. Cherubism: clinicoradiographic features, treatment and long-term follow-up of 8 cases. J Oral Maxillofac Surg 2007;65(3):517-22.

13. Caballero R, Vinals H. Cherubism: a study of three generations. Med Oral 1998;3(3):163-71.

14. Jones WA, Gerrie EJ, Pritchard J. Cherubism-familial fibrous dysplasia of the jaws. J Bone Joint Surg Br 1950;32-B(3):334-47.

15. Lannon DA, Earley MJ. Cherubism and its charlatans. Br J Plast Surg 2001;54(8):708-11.

16. Pulse CL, Moses MS, Greenman D, Rosenberg SN, Zegarelli DJ. Cherubism: case reports and literature review. Dent Today 2001;20(11):100-3. 
17. Wang CN, Song YL, Peng B, et al. The aggressive form of cherubism: report of two cases in unrelated families. $\mathrm{Br} \mathrm{J}$ Oral Maxillofac Surg 2006;44(4):322-4.

18. Hart W, Schweitzer DH, Slootweg PJ, Grootenhuis LS. Man with cherubism. Ned Tijdscha Geneested 2000;144(1):34-8.

19. Beaman FD, Bancroft LW, Peterson JJ, Kransdorf MJ, Murphey MD, Menke DM. Imaging characteristics of cherubism. AJR Am J Roentgenol 2004;182(4):1051-4.

20. Ozkan Y, Varol A, Turker N, Aksaballi N, Basa S. Clinical and radiological evaluation of cherubism: a sporadic case report and review of the literature. Int J Pediatr Otorhinolaryngol 2003;67(9):1005-12.

21. Penarrocha M, Bonet J, Minguez JM, Bagan JV, Vera F, Muiguez I. Cherubism: a clinical, radiographic and histopathologic comparison of 7 cases. J Oral Maxillofac Surg 2006;64(6):924-30.

22. Arnott DG. Cherubism-an initial unilateral presentation. Br J Oral Surg 1978; 16(1):38-46.

23. Ramon Y, Engelberg IS. An unusually extensive case of cherubism. J Oral Maxillofac Surg 1986;44(4):325-8.
24. Meng XM, Yu SF, Yu GY. Clinicopathologic study of 24 cases of cherubism. Int J Oral Maxillofac Surg 2005;34(4):350-6.

25. Li CY, Yu SF. A novel mutation in the $\mathrm{SH}_{3} \mathrm{BP} 2$ gene causes cherubism: case report. BMC Med Genet 2006;7:84.

26. Hatani $\mathrm{T}$, Seda K. Adaptor protein $3 \mathrm{BP} 2$ and cherubism. Curr Med Chem 2008;15(6):549-54.

27. Roginsky VV, Ivanov AL, Ovtchinnikov IA, Khonsari RH. Familial cherubism: the experience of the Moscow Central Institute for Stomatology and Maxillo-facial Surgery. Int J Oral Maxillofac Surg 2009;38(3):218-3.

28. Raposo-Amaral CE, de Campos Guidi M, Warren $\mathrm{SM}$, et al. Two-stage surgical treatment of severe cherubism. Ann Plast Surg 2007;58(6):645-51.

29. de Lange J, van den Akker HP, Scholtemeijer M. Cherubism treated with calcitonin: report of a case. J Oral Maxillofac Surg 2007;65(8):1665-7.
Access full text article on other devices

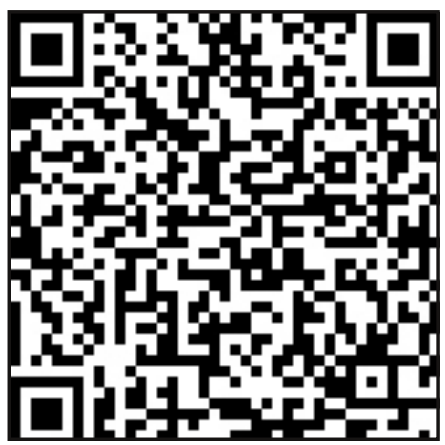

Access PDF of article on other devices

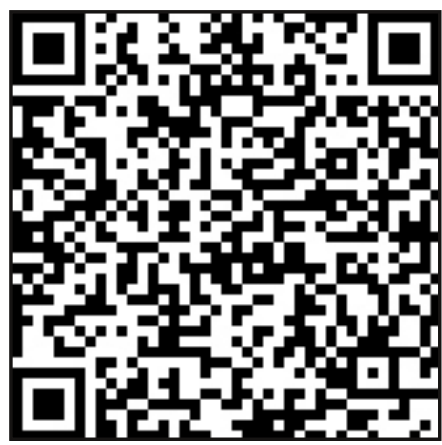

